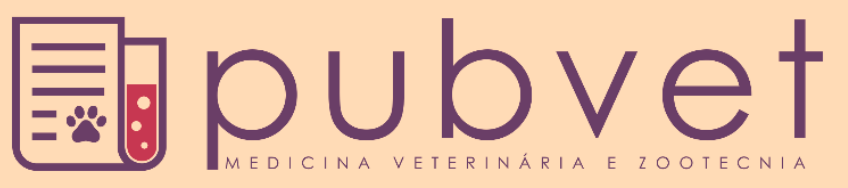

https://doi.org/10.31533/pubvet.v15n08a892.1-5

\title{
Alterações congênitas em filhotes da raça Pug decorrente de acasalamento consanguíneo: Relato de caso
}

\author{
Leticia Baldassaune de Holanda ${ }^{*} \bullet$, Thalia Vitória Mariussi ${ }^{2} \bullet$, Sophie Caroline Quatrin ${ }^{3} \bullet$, \\ Monica Regina de Matos $^{4} \odot$ \\ ${ }^{I}$ Discente da Pontifícia Universidade Católica do Paraná (PUCPR), Departamento de Medicina Veterinária. Toledo -PR Brasil. \\ ${ }^{2}$ Médica Veterinária, residente em clínica médica e cirúrgica de animais de companhia na PUCPR, Toledo- PR Brasil. \\ ${ }^{3}$ Médica veterinária, pós-graduada em Clínica Médica e Cirúrgica de Pequenos Animais (UNICESP), Toledo-PR Brasil. \\ ${ }^{4}$ Doutoranda na Universidade do Oeste do Paraná na área de Recursos Pesqueiros e Engenharia de Pesca, docente na Pontifícia Universidade \\ Católica do Paraná - Departamento de patologia. Toledo-PR Brasil. \\ *Autor para correspondência, E-mail: Leticia_hholanda@hotmail.com
}

Resumo. Os cruzamentos entre indivíduos com alto grau de parentesco geram, com frequência, deformidades aos fetos. A endogamia propicia formação de genes recessivos que ocasionam defeitos acrossomais responsáveis por malformações que podem trazer riscos à vida do neonato. O objetivo foi relatar o acompanhamento e atendimento a um parto de uma cadela da raça pug cujo cruzamento deu-se com o avô, gerando consanguinidade e ocasionando dois neonatos que apresentaram malformações congênitas. O animal chegou à Clínica Veterinária Tolevet, localizada em Toledo - Paraná, em trabalho de parto, apresentando contrações uterinas e aumento de volume na região do útero no abdômen. Ao exame físico, parâmetros vitais apresentavam-se normais. No parto nasceram sete filhotes que receberam os cuidados de retirada da bolsa placentária, desobstrução das vias aéreas e ligadura umbilical. Dois filhotes apresentaram deformidade congênita, um apresentou lábio leporino concomitante com fenda palatina (palatosquise), o segundo, já em estado de óbito, apresentou acúmulo anormal de líquido em tecido fetal totalmente edemaciado, definido como hidropisia fetal. Este trabalho demonstra a importância de que se evitem acasalamentos consanguíneos de ancestrais comuns, a fim de minimizar a incidência de defeitos congênitos em neonatos incompatíveis com a vida ou que trazem risco à saúde e à qualidade de vida do animal.

Palavras-chave: Congênito, consanguinidade, malformações, neonato

\section{Congenital changes in Pug puppies due to inbreeding: Case report}

\begin{abstract}
Crossbreeding between individuals with a high degree of kinship often generate deformities to the fetuses. Inbreeding provides the formation of recessive genes that cause acrosomal defects responsible for malformations that can bring risks to the newborn's life. The objective was to report the follow-up and attendance to a delivery of a female PUG breed whose crossing took place with her grandfather, generating inbreeding and causing two neonates who had congenital malformations. The animal arrived at Tolevet - the veterinary clinic -, located in Toledo - Paraná, in labor, presenting uterine contractions and swelling in the region of the uterus in the abdomen. On physical examination, vital parameters were normal. At birth, seven puppies were born who received the care of removing the placental pouch, clearing the airways and umbilical ligation. Two puppies had congenital deformity; one had concurrent cleft lip with cleft palate (palatoschisis), the second, already in a state of death, presented abnormal fluid accumulation in fully edematous fetal tissue, defined as fetal hydrops. This report demonstrates the importance of avoiding common ancestors consanguineous mating, in order to minimize the incidence
\end{abstract}


of birth defects in neonates that are incompatible with life or that pose a risk to the animal's health and quality of life.

Keywords: Congenital, consanguinity, malformation, neonate

\section{Introdução}

As malformações congênitas podem ser originadas por causas hereditárias, fatores ambientais, infecciosos, nutricionais e/ou pela relação de ambos (Damé et al., 2013; Riet-Correa et al., 2007). Segundo Cabral-Oliveira et al. (2007) a maior parte dos defeitos congênitos genéticos apresentados em animais são transmitidos por genes autossômicos recessivos, o que leva a diferenciação no nascimento dos animais. Esses defeitos podem ser fatais, semi fatais ou causam alterações somente estéticas compatíveis com a vida, não afetando os animais (Johnson et al., 1985).

O cruzamento entre seres mais proximamente aparentados entre si, ao se comparar com o restante da população, é definido como endogamia. Portanto, quando os pais de um indivíduo têm um ou mais ancestrais em comum, eles são considerados parentes próximos, gerando consanguinidade e genes recessivos presentes com frequência, sendo estes beneficiários ou prejudiciais (Souza et al., 2010).

Destacam-se dentre as anomalias mais frequentes nos animais domésticos o lábio leporino, podendo ser uni ou bilateral, que gera a falta de continuidade nos processos nasais medial e maxilar (Ribeiro et al., 2007). Esta pode ser concomitante com a fenda palatina, ou palatosquise, defeito longitudinal de extensão variável que afeta osso e mucosas da linha média do palato duro. Cães de raças braquicefálicas (Bulldog francês, Pug, Boston terrier, Pequinês, Boxer, Bulldog inglês e Shih tzu) estão sob maior ameaça que outras raças (Lopes et al., 2019). Outra deformidade, sendo menos comum, porém altamente relevante, é a Hidropisia Fetal, caracterizada por edema cutâneo generalizado, com acúmulo anormal de líquido em todos os tecidos fetais, também apresenta causa de anormalidade cromossomal consequente da consanguinidade (Montenegro et al., 2014).

Este relato de caso objetiva apresentar três deformidades congênitas fetais em dois neonatos da raça pug, consequentes de um cruzamento entre dois cães com alto grau de parentesco, ocasionando a consanguinidade entre os reprodutores.

\section{Relato do caso clínico}

Foi atendida na Clínica Veterinária Tolevet, situada em Toledo - Paraná, uma cadela da raça Pug, adulta, de $9,8 \mathrm{~kg}$, em trabalho de parto. A mesma foi encaminhada pelo tutor para realizar acompanhamento obstétrico assistido, para assegurar a saúde da mãe e para que os neonatos nascessem com os devidos cuidados pós-parto. Durante o atendimento o tutor relatou que a paciente acasalou com um cão que convivia na mesma casa, sendo este cão seu avô. Acompanhado da paciente veio um filhote que nasceu em casa, estando o mesmo saudável.

Ao exame físico da cadela constatou-se mucosas normocoradas, frequência cardíaca de 130 batimentos por minuto (bpm), tempo de preenchimento capilar (TPC) menor que três segundos, temperatura retal de 37,2 graus, hidratada e linfonodos submandibulares e pré-escapulares sem alterações. Durante a palpação abdominal foi possível observar aumento de volume em região uterina.

As contrações uterinas ocorreram normalmente, não sendo necessários estimulantes hormonais. Ao todo nasceram sete filhotes, todos tiverem a bolsa placentária rompida com auxílio veterinário, em seguida as vias respiratórias superiores foram desobstruídas com compressas estéreis e massagem para estimular a respiração, foi realizada a ligadura dos cordões umbilicais com fio de nylon 3,0. Após estes procedimentos, o neonato era entregue para o reconhecimento materno e amamentação.

Durante este período de trabalho de parto, o qual perdurou por 5 horas e meia, dois dos sete filhotes apresentaram deformações físicas patológicas relevantes. Um deles nasceu natimorto e apresentou edema generalizado, sendo observado acúmulo de líquido em todo o subcutâneo (Figura 1), sendo a patologia diagnosticada como hidropisia fetal. Enquanto o outro neonato nasceu com batimentos cardíacos e respiração presentes, apresentando fissura labial no lábio superior, diagnosticado como lábio 
leporino (Figura 2) e, juntamente ao lábio leporino, a abertura em toda região de palato duro, diagnosticado como fenda palatina (Figura 3 ).

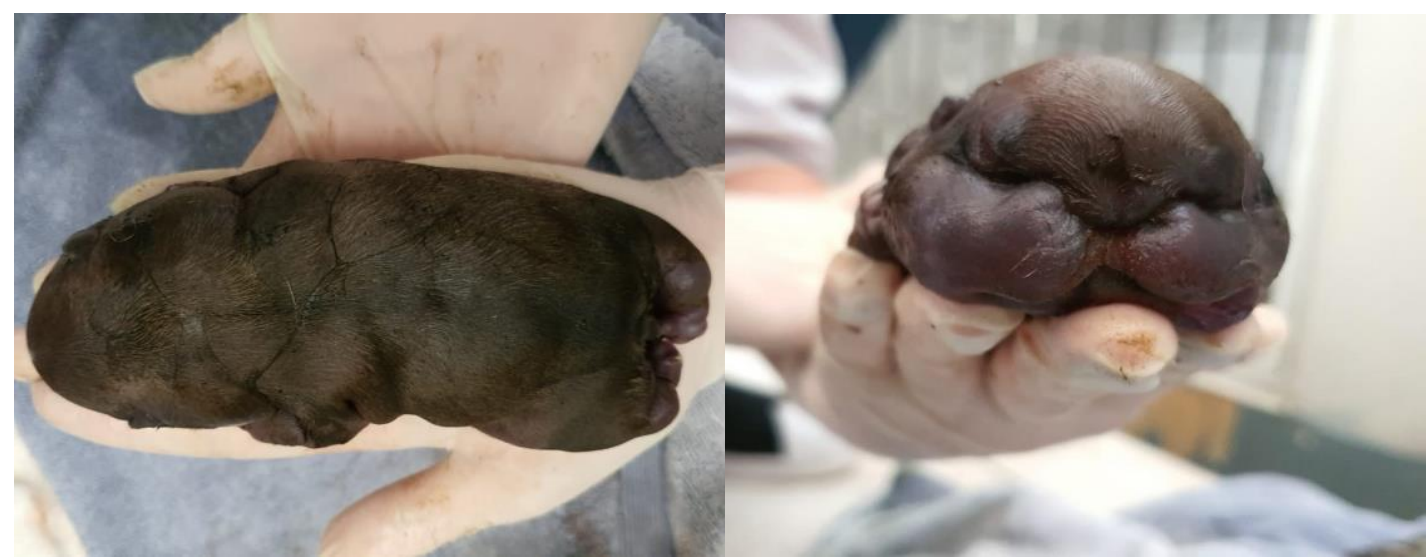

Figura 1. Neonato natimorto com edema generalizado e presença de líquido em excesso em toda extensão subcutânea.

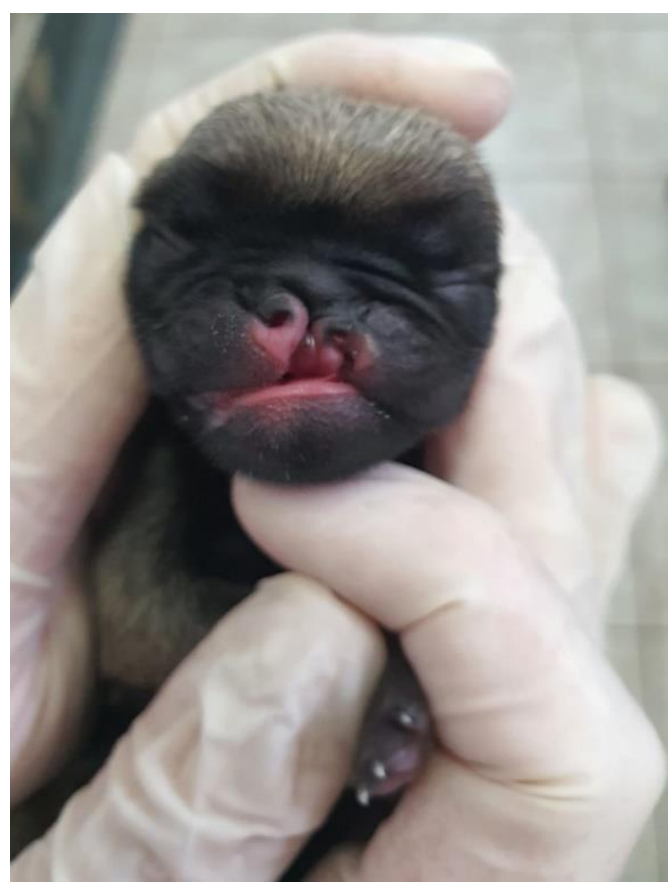

Figura 2. Neonato com fissura labial no lábio.

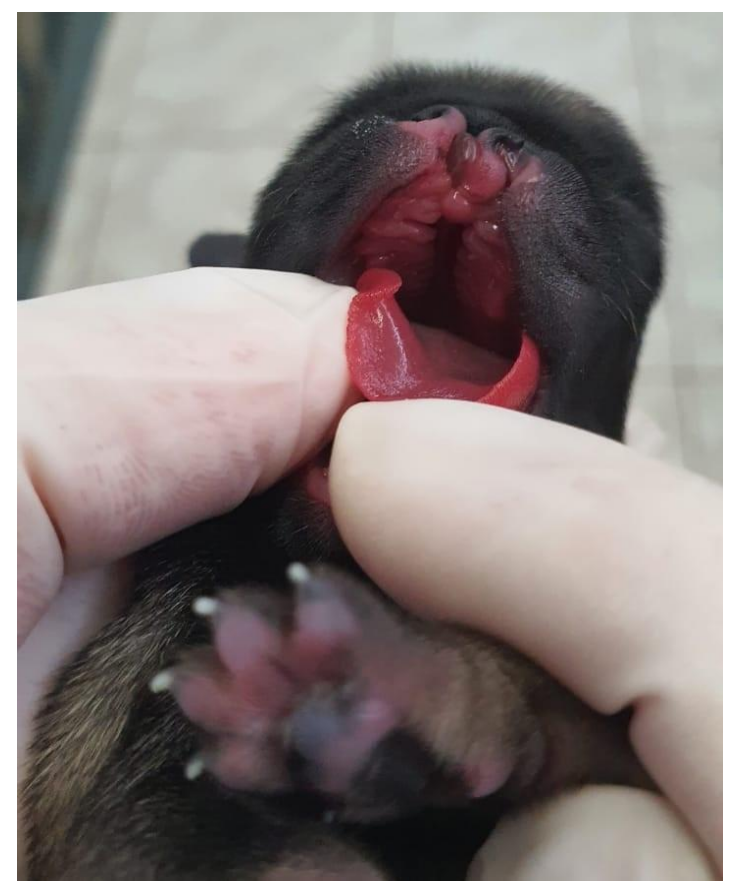

Figura 3. Neonato com abertura em toda região do palato duro.

\section{Discussão}

O cruzamento entre familiares (mãe e avô) acarretou as malformações descritas neste relato e vistas nas figuras acima corroborando com a afirmação de Prestes \& Landim-Alvarenga (2017) o qual aponta que esse tipo de cruzamento na maioria das vezes gera aparecimento de falhas hereditárias, tendo em vista que o cruzamento de animais com parentesco estreito facilita a manifestação de genes recessivos indesejáveis.

O primeiro filhote diagnosticado com fenda palatina nasceu em condições viáveis compatíveis com a vida (Gioso, 2003; San Román, 1999), mesmo sendo muito visível, pode não acarretar graves complicações clínicas no paciente. A fenda palatina encontrada no filhote em questão, estendia-se por todo palato na direção longitudinal, mediana, classificada como fenda palatina do tipo secundário ou fenda palatina completa, desinente da falta da fusão do palato duro, palato mole ou das duas estruturas unidas (García-Arnas et al., 1991).

Após a saída das células da crista neural, forma-se o tecido conectivo e o esqueleto da face. O lábio leporino é então formado pelas falhas na fusão do processo fronto-nasal com o maxilar durante a $4^{\circ} \mathrm{e}$ a $8^{\circ}$ semana do desenvolvimento embrionário. Esta condição pode ocasionar transformações incorrigíveis 
no comportamento celular da crista neural e consequentemente no mesênquima facial, acarretando dessa forma o nascimento de um feto portador de fissura em lábio e /ou palato (Ribeiro \& Moreira, 2005).

Os sinais clínicos das fissuras labiais são representados por anormalidade que compreende os lábios, gengiva e dentes (Peterson \& Kutzler, 2011), sinais estes que foram notados logo após o nascimento do neonato. Em pequenos animais, o lábio leporino é diagnosticado no momento do nascimento, diante de exame clínico simples é possível observar a fissura anormal no lábio superior, não se fazendo necessário o exame radiográfico do crânio (Fossum, 2014; San Román, 1999), por isso o diagnóstico pôde ser concluído logo após o nascimento com a inspeção visual.

Em animais, o tratamento cirúrgico reconstrutor labial (queiloplastia) e fissura palatina (palatoplastia) tem caráter primariamente estético (Gioso, 2003); porém, segundo Fossum (2014) alguns neonatos acometidos não são capazes de se alimentar mamando efetivamente logo após o nascimento, outros ainda apresentam a cavidade nasal contaminada por alimentos e saliva, pneumonia aspirativa, sinais de rinite e algumas outras infecções respiratórias também são comuns, por isso de acordo com Ribeiro et al. (2007), o filhote deve ser operado de 8 a 12 semanas de idade, quando o paciente adquire as condições orgânicas primordiais e necessárias para ser submetido à anestesia geral.

O neonato hidrópico apresentou tamanho desproporcional em comparação com os demais, derrame subcutâneo e edemas, corroborando com estudos apresentados por Rodrigues et al. (2016) que relatam que os fetos acometidos pela hidropsia, do tipo anasarca, apresentam excesso de líquido no tecido subcutâneo.

Segundo Bukowski \& Saade (2000), as anomalias cromossómicas constituem também uma causa frequente de hidropsia fetal não imune. As situações patológicas subjacentes, responsáveis pelo desenvolvimento de hidropsia nestes fetos, são geralmente as anomalias cardiovasculares, a hipoalbuminemia e as malformações linfáticas (Rodrigues et al., 2016). O prognóstico para os fetos com hidropsia fetal não imune é, de maneira geral, desfavorável, dependendo, no entanto, da causa subjacente.

Após o nascimento foi constatado óbito, sem qualquer possibilidade de alguma manobra para reanimação, o que segue percentuais que apontam taxa de mortalidade perinatal varia entre os $60 \%$ e os 100\%, em casos de neonatos humanos (Ansersen et al., 1983). Ribeiro \& Moreira (2005) e Dutra (2008) citam que ainda não é possível determinar com exatidão um fator causal, porém determinam alguns fatores que corroboram para tal deformidade, como por exemplo o fator genético e a consanguinidade, fator este presente nos filhotes relatados, já que seus genitores eram parentes, o que possivelmente tenha dado consequência para a existência desta malformação.

\section{Conclusão}

As malformações congênitas ocasionadas pela consanguinidade revelam consequências físicas aos animais que as apresentam, tendo a possibilidade de serem corrigidas futuramente de modo cirúrgico ou levando o feto a óbito, dependendo de sua gravidade. $O$ tratamento cirúrgico de lábio leporino e fenda palatina, quando realizados prezam razões estéticas inicialmente, porém a fissura palatina gera ao neonato impossibilidades de alimentação de imediato e predisposição a doenças secundarias que geram danos a sua qualidade de vida. A hidropsia fetal é incompatível com a vida, pode resultar em distocia obstrutiva tendo em vista que o feto será muito grande. Portanto, é sempre necessário informar e alertar os tutores sobre os riscos de acasalamento entre ancestrais em comum muito próximos, para evitar filhotes com defeitos congênitos que causam riscos à saúde e vida do animal.

\section{Referências}

Ansersen, H. M., Drew, J. H., Beischer, N. A., Hutchison, A. A., \& Fortune, D. W. (1983). Non-immune hydrops fetalis: changing contribution to perinatal mortality. An International Journal of Obstetrics \& Gynaecology, 90(7), 636-639. https://doi.org/10.1111/j.1471-0528.1983.tb09281.x.

Bukowski, R., \& Saade, G. R. (2000). Hydrops fetalis. In F. D. Malone \& M. E. D’Alton (Eds.), Clinics in Perinatology. WB Saunders Company.

Cabral-Oliveira, F. C. L., Albuquerque, L. C., São Paulo, C., Lacerda, A. M., Fortuna, F. N., Farias, S., 
Portela, D., Christi, A., \& Acosta, A. X. (2007). Defeitos Congênitos-tópicos relevantes. Gazeta Médica Da Bahia, 77(1), S32-S39.

Damé, M. C. F., Riet-Correa, F., \& Schild, A. L. (2013). Doenças hereditárias e defeitos congênitos diagnosticados em búfalos (Bubalus bubalis) no Brasil. Pesquisa Veterinária Brasileira, 33(7), 831839. https://doi.org/http://dx.doi.org/10.1590/S0100-736X2013000700001.

Dutra, A. T. (2008). Defeitos palatinos congênitos. In Medicina Veterinária: Vol. Master. Universidade Castelo Branco.

Fossum, T. W. (2014). Cirurgia de pequenos animais (4th ed., Vol. 1). Elsevier Brasil.

García-Arnas, F., Llorens, M. P., San Román Ascaso, F., Prandi Chevalier, D., \& Peña Giménez, M. A. (1991). Palatosquisis en la especie canina. Clínica Veterinaria de Pequeños Animales, 11(1), 46-53.

Gioso, M. A. (2003). Odontologia para o clínico de pequenos animais (5a ed., Vol. 15). Leditora.

Johnson, J. L., Leipold, H. W., \& Hudson, D. B. (1985). Prominent congenital defects in Nebraska beef cattle. Breeding and Reproduction, 4(7), 1-8.

Lopes, T. H. L., Barros, H. B. S., Freitas, J. C. C., Domingos, L. S., Araujo, A. F., FIGUEIREDO, M. A. P., Schons, S. V, \& Manrique, W. G. (2019). Malformações faciais congênitas em cão: relato de caso. Ars Veterinaria, 35(2), 73-77.

Montenegro, C. A. B., Pritsivelis, C., \& Rezende Filho, J. (2014). Hidropisia fetal não imune. Femina, 42, 277-282.

Peterson, M. E., \& Kutzler, M. (2011). Small animal pediatrics: the first 12 months of life. Elsevier Health Sciences.

Prestes, N. C., \& Landim-Alvarenga, F. C. (2017). Obstetrícia veterinária. Guanabara Koogan.

Ribeiro, A. A., Leal, L., \& Thuin, R. (2007). Análise morfológica dos fissurados de lábio e palato do Centro de Tratamento de Anomalias Craniofaciais do Estado do Rio de Janeiro. Revista Dental Press, 12(5), 109-118.

Ribeiro, E. M., \& Moreira, A. S. C. G. (2005). Atualização sobre o tratamento multidisciplinar das fissuras labiais e palatinas. Revista Brasileira Em Promoção Da Saúde, 18(1), 31-40.

Riet-Correa, F., Méndez, F., Carmen Schild, M., Riet-Correa, A. L. F., Schild, A. L., \& Carmen, M. M. (2007). Doenças de ruminantes e eqüinos. Varela.

Rodrigues, D. S. A., Medeiros, B. L. N., Alencar, D. F., Barros, D. A., Santos, M. M., Barbosa, Y. G. S., Rodrigues, M. C., \& Silva, F. L. (2016). Hidropsia fetal em neonato de cadela da raça Bulldog Francês-Relato de caso. PUBVET, 10(6), 466-469. https://doi.org/10.22256/pubvet.v10n6.466-469.

San Román, F. (1999). Atlas de odontologia de pequenos animais. São Paulo, 1, 217-241.

Souza, J. C., Perotto, D., Abrahão, J. J., Freitas, J. A., Ferraz Filho, P. B., Weaber, R. L., \& Lamberson, W. R. (2010). Estimativa das distâncias genéticas e componentes principais em bovinos de corte no Brasil. Archivos de Zootecnia, 59(228), 479-485. https://doi.org/10.21071/az.v59i228.4703.

Histórico do artigo:

Recebido: 20 de abril de 2021

Aprovado: 24 de maio de 2021
Licenciamento: Este artigo é publicado na modalidade Acesso Aberto sob a licença Creative Commons Atribuição 4.0 (CC-BY 4.0), a qual permite uso irrestrito, distribuição, reprodução em qualquer meio, desde que o autor e a fonte sejam devidamente creditados. 